\title{
Managing the Psychosocial and Financial Consequences of Living Donation
}

\author{
Mary Amanda Dew • Larissa Myaskovsky • \\ Jennifer L. Steel • Andrea F. DiMartini
}

Published online: 6 December 2013

(C) Springer International Publishing AG 2013

\begin{abstract}
There has been dramatic growth in the last decade in the literature on psychosocial and financial impacts of living organ donation. With this growth has come recognition that these impacts must be considered when educating prospective donors about the donation process and when planning donor follow-up care after donation. Our review highlights recent studies that provide new information on the nature of psychosocial and financial outcomes in living donors, with special attention to studies examining unrelated donors (i.e., those with no biologic or longstanding emotional connection to the transplant patient), given that these individuals represent a growing segment of the living donor population. Limitations and gaps in available evidence are noted. We also discuss recent recommendations for post-donation
\end{abstract}

M. A. Dew ( $\square)$

Departments of Psychiatry, Psychology, Epidemiology, Biostatistics, and Clinical and Translational Science, University of Pittsburgh School of Medicine and Medical Center, 3811 O'Hara Street, Pittsburgh, PA 15213, USA

e-mail: dewma@upmc.edu

L. Myaskovsky

Departments of Medicine, Psychiatry and Clinical and Translational Science, University of Pittsburgh School of Medicine and Medical Center and Center for Health Equity Research and Promotion, VA Pittsburgh Healthcare System, 230 McKee Place, Suite 600,

Pittsburgh, PA 15213, USA

e-mail: myaskovskyl@upmc.edu

\section{J. L. Steel}

Departments of Surgery, Psychiatry and Psychology, University of Pittsburgh School of Medicine and Medical Center, 3459 Fifth Avenue; MUH 7S, Pittsburgh, PA 15213, USA

e-mail: steelj1@upmc.edu

\section{A. F. DiMartini}

Departments of Psychiatry and Surgery, University of Pittsburgh

School of Medicine and Medical Center, 3811 O'Hara Street,

Pittsburgh, PA 15213, USA

e-mail: dimartiniaf@upmc.edu monitoring of donors' psychosocial and financial outcomes, and we consider advances in evidence regarding interventions and prevention strategies to minimize any adverse psychosocial and financial impacts of living donation.

Keywords Living donors $\cdot$ Kidney donors $\cdot$ Liver donors · Psychosocial outcomes $\cdot$ Financial outcomes $\cdot$ Health-related quality of life

\section{Introduction}

The psychosocial and financial consequences of living organ donation have received greater attention in recent years than at any point in the history of living donation. Although there continue to be gaps in our understanding of these consequences, there is increasing recognition that they matter to donors, and deserve attention and care from transplant professionals as well. Moreover, psychosocial outcomes, as well as financial considerations and burden on donors have moved front and center as both the U.S. and worldwide transplant communities work to maximize donor safety and minimize adverse impacts on donors. Thus, not only have researchers sought to provide data to fully delineate specific psychosocial and financial consequences of donation, but consensus conferences and work groups have considered these issues with an eye toward the development of guidelines and national policy regarding the evaluation and selection of living donors, and the follow-up monitoring and care that they require $[1,2 \bullet$, $3,4]$. In the U.S., policies governing living donor kidney transplantation have been expanded to delineate psychosocial issues that must be considered in donor selection, and to specify the psychosocial and financial risks that must be described to potential donors when gaining their informed consent [5]. 
In the present review, we highlight recent advances pertinent to the management of living donor psychosocial and financial outcomes, as well as comment on critical limitations and gaps in available information. A prerequisite for optimal management is an understanding of the range of observed outcomes. Thus, we consider important recent studies that provide new information on the nature of psychosocial and financial outcomes across the population of living donors. We specifically highlight recent studies examining these outcomes within a segment of the living donor population that is increasing in size: unrelated donors (i.e., those with no biologic or longstanding emotional connection to the transplant patient), including individuals who donate anonymously or through kidney paired donation programs. We then discuss recent recommendations for post-donation monitoring of donors and changes in U.S. national policy regarding donor follow-up that have implications for the optimal management of donor psychosocial and financial outcomes. Finally, we consider advances and gaps in evidence regarding the effectiveness of management strategies.

\section{The nature and Risk Factors for Psychosocial and Financial Outcomes}

\section{Psychosocial Outcomes}

Psychosocial outcomes encompass specific reactions to the donation experience (e.g., positive feelings about the experience or oneself as a person, as well as negative reactions such as regret at having donated). Psychosocial outcomes also include elements of health-related quality of life (HRQOL), i.e., patients' well-being as impacted by any medical condition or treatment [6]. In donors, this includes (a) somatic symptoms and perceptions of physical well-being; (b) psychological symptoms and well-being; and (c) social well-being and functioning in relationships with the transplant recipient, other family members, and friends.

Recent reviews of the literature on these outcomes in living kidney and liver donors have shown that, on average, donors have positive feelings about the donation experience, show little to no regret at having donated, and have high levels of HRQOL both before and after donation [7-10]. Their mean HRQOL levels generally exceed those of the general population [7-10]. But it is equally clear that relying on averages does not tell the whole story. Sizable proportions of the living donor population experience psychosocial difficulties after donation. For example, as summarized in one review [8], elevated psychological distress and/or diagnosable psychiatric disorders have been documented in about one in every four living donors, including incident cases in individuals with no pre-donation history of disorder. Up to one-third of donors report that their health is fair to poor or markedly worse since donation, with persistent fatigue and pain being relatively common complaints.

Recent reviews have also identified key gaps in evidence concerning psychosocial outcomes [10, 11•]. For example, most studies focus on the early months and years postdonation with little consideration of longer-term outcomes. In addition, there is limited information on risk factors for poor outcomes. Several recent reports have provided new information on both issues. These studies, described in Table 1, are noteworthy in coming from several different countries, and assessing large living kidney and liver donor cohorts that include individuals who donated as many as 48 years earlier. Several of the reports not only compared donor HRQOL outcomes to normative data (i.e., national samples selected to be representative of the general population and used in the initial psychometric validation of the HRQOL instrument in question) but also drew comparison data from other community-based surveys $[12 \bullet, 16 \bullet]$ or constructed a comparison group of non-donors who were demographically and medically similar to donors [15•]. The studies' findings suggest that, on average, very favorable donor psychosocial outcomes are observed even many years post-donation, relative to normative or other comparative samples. However, like the relatively large literature on short-term HRQOL outcomes, these long-term follow-up reports also identify subgroups of donors with impaired physical, psychological, and social HRQOL. Rates of impairment in HRQOL domains (as defined based on study-specific thresholds) range from $5 \%$ to $20 \%$ across the studies in Table 1 .

Such impairment rates are seen in samples followed up many years post-donation might arguably reflect the base rates of these problems that would be seen in any community-based population and, hence, would be unrelated to donation. It is, therefore, interesting to note the range of donation-related predictors and correlates of HRQOL outcomes that were identified across these reports, as shown in Table 1. The most consistent correlates of poor HRQOL at follow-up were greater BMI at donation (a risk factor for impaired physical HRQOL), and donors' reports that they had negative psychological outcomes early post-donation or had longer recovery times. Donors' early post-donation reactions were assessed only retrospectively at follow-up. Thus, their recall may have been colored by current HRQOL rather pinpointing important risk factors for follow-up HRQOL. However, the BMI assessments were obtained from medical records from the time of donation. These findings suggest that BMI may be a central factor to consider during donors' medical evaluation not only due to its increasing prevalence in donors and potential impact on medical outcomes [17] but due to its role in increasing risk for poor psychosocial outcomes. The mechanism by which BMI may affect psychosocial outcomes remains unknown, but it has been suggested to stem from its impact on risk for surgical complications and other post-donation health 


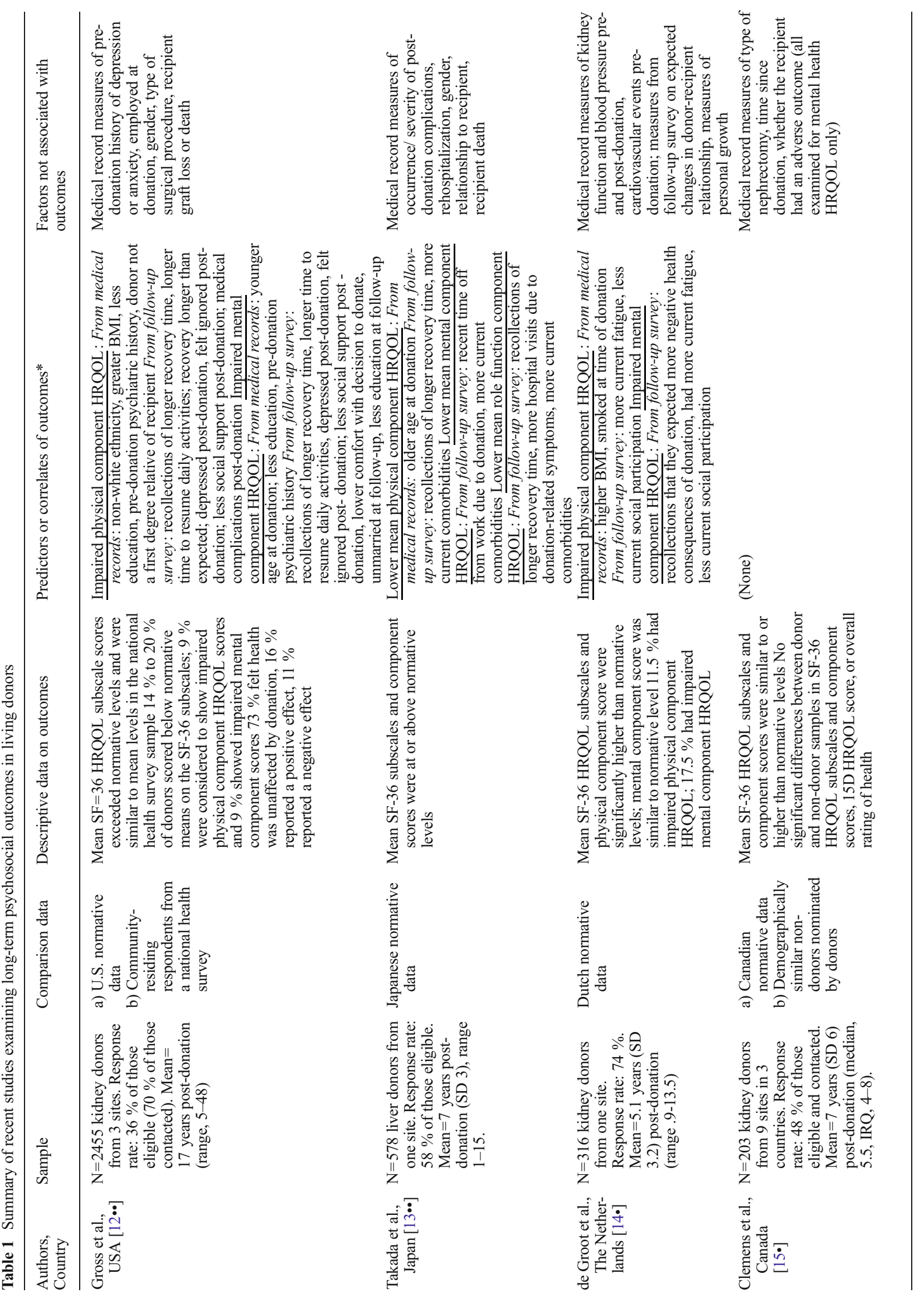


problems [12••, 14•]. Additional work directly examining such mechanisms would be important for developing strategies to mitigate any psychosocial impacts of BMI in donors.

Among other risk factors considered in the recent studies, it is noteworthy that the studies failed to find that recipient status (i.e., whether the recipient suffered graft loss or death) was related to donor long-term HRQOL outcomes. The occurrence of early post-donation donor complications was inconsistently associated with HRQOL, as was the donor's relationship to the recipient, although the vast majority of donors in these studies were first-degree relatives of their recipients.

Although these recent reports expand our understanding of the nature and correlates of long-term HRQOL, their generalizability may be limited because response rates were in some cases relatively low (see Table 1), and there were often important differences between follow-up survey responders and nonresponders. In addition, there are important differences between donors who donated even five years ago (much less 30 to 40 years ago) and today's donors in demographics, medical characteristics, and relationship to transplant recipients. For example, current donors in the U.S. include a much higher proportion of ethnic minorities, have more medical comorbidities at donation, and are less likely to be closely emotionally or biologically related to their recipients than are the donors described in the recent long-term follow-up studies $[2 \cdot 11 \bullet]$. Because of the changing composition of the donor population, both short-term and long-term psychosocial outcomes and their risk factors require ongoing assessment. Furthermore, rather than relying on making comparisons of donors to normative data (which were collected largely during the psychometric development of the HRQOL instruments), it would be important for studies to routinely incorporate relevant comparison groups selected specifically to enable better identification of unique impacts of donation on HRQOL. Work by Clemens et al. [15•] in Table 1 presents one example of an attempt to construct a comparison group of individuals who would be expected to be similar to donors in major respects but who did not undergo donation.

Another limitation that the studies in Table 1 share with previous literature is the almost exclusive focus on generic HRQOL measures, rather than consideration of donationspecific HRQOL measures or in-depth measurement of certain domains of well-being that may be more relevant to unique issues and concerns faced by donors. For example, it has been suggested that diagnosable depression, anxiety and other negative psychological reactions may be important sequelae of living donation that often go unrecognized [7, 12••]. Recent work by Lentine and colleagues $[18 \cdot \bullet]$ is, therefore, notable because it considered both the prevalence and correlates of depressive disorders in a national sample of kidney donors, based on an analysis of billing claims of a private health insurer. From the start of insurance benefits (at a median of 4.9 years post-donation) to one year later, Lentine et al. 
found that $4.2 \%$ of their cohort of 4650 donors experienced diagnosed depression and $11.5 \%$ had experienced depression by five years later. Although depression was less common in these donors than in age-matched and gender-matched general insurance beneficiaries, the risk of depression was significantly elevated among donors who were female, white, or required reoperation after initial donation surgery. Among non-spousal unrelated donors, recipient death or graft failure more than doubled the risk of depression. Recipient outcomes did not increase related donors' depression risk.

Finally, a recent synthesis of qualitative studies examining kidney donors' reactions to the donation experience helps to round out the picture of the wide-ranging impact of donation on donors' lives. Across 26 studies, Tong et al. [19] concluded that several themes dominated donors' views of their experience (Table 2). Each theme included a mixture of both negatives and positives, reflecting losses and difficulties as well as personal benefits. This mixture illustrates the complexity of the reactions that donors may have.

\section{Financial Impacts}

The financial impacts of donation encompass out-of-pocket costs; lost wages or loss of employment; difficulties in obtaining or retaining health and life insurance; and hardships that may be more difficult to assess empirically (e.g., financial hardship, reflecting the ability to absorb costs). The impacts may extend to the donor's family. The degree of impact ranges across a spectrum from the severely negative consequences experienced by organ vendors in countries where vending and trafficking continue to prevail, to the burden experienced by donors in countries where the organ transplantation system is highly regulated and is designed to prevent coercion of donors and promote their health and safety.
Organ vending and trafficking have been repeatedly shown to have not only extremely high physical and psychological costs for vendors, but also socioeconomic costs $[9,20]$. A recent qualitative study vividly captures these costs in Bangladeshi kidney donors, calling such activity a form of bioterrorism that leaves impoverished persons in significantly worsened circumstances than before donation [21]. There is an international consensus that this type of activity should be prohibited [22].

In countries with strict standards to protect donor safety, where prospective donors are carefully evaluated to determine that they have no expectation of remuneration, there unfortunately also continue to be some significant financial burdens associated with living donation. A small literature has accrued within the last ten years, mostly from North America, and focused on living kidney donors, showing that (a) concerns about the financial impact of donation affect the pursuit of living donor transplantation by transplant candidates, potential donors, and transplant programs, and (b) significant proportions of donors report costs and financial hardship attributable to donation and recovery from surgery. For example, twothirds of kidney transplant candidates report concerns about such effects on potential living donors [23], and more than one-third of living donor kidney and liver transplant programs reported that prospective donors themselves declined the option of donation due to reservations about finances and insurability [24]. At donation, $18 \%$ to $25 \%$ of kidney donors are uninsured $[25,26]$. After donation, up to almost one-quarter of kidney donors report financial hardships attributable to donation $[16 \bullet, 27,28 \bullet$. Although Clemens et al. [15•] recently found no differences in employment rates between kidney donors and non-donor comparison group members, implying no impact of donation on employment per se, living donation exerts other costs. For example, $25 \%$ to $30 \%$ of employed kidney donors do not have sufficient medical leave and/or vacation time to cover their surgical recovery [27, 28•]. In

Table 2 Results from systematic analysis of qualitative studies of kidney donors' reactions to the donation experience

\begin{tabular}{|c|c|c|c|}
\hline \multirow{2}{*}{$\begin{array}{l}\text { Elements of } \\
\text { the experience }\end{array}$} & \multicolumn{3}{|c|}{ Major themes describing donors' experiences } \\
\hline & Renegotiating one's identity & Renegotiating roles & Renegotiating relationships \\
\hline Negative elements & $\begin{array}{l}\text { - Feelings of fear and } \\
\text { vulnerability } \\
\text { - Having a sense of loss } \\
\text { - Depression } \\
\text { - Guilt }\end{array}$ & $\begin{array}{l}\text { - Fears about being able to resume } \\
\text { previous activities } \\
\text { - Problems fulfilling multiple simultaneous } \\
\text { roles (e.g., being a donor as well as a } \\
\text { parent, caregiver, etc.) }\end{array}$ & $\begin{array}{l}\text { - Feeling neglected } \\
\text { - Feeling proprietorial } \\
\text { concern and worry abou } \\
\text { the recipient }\end{array}$ \\
\hline Positive elements & $\begin{array}{l}\text { - Gaining a new } \\
\text { appreciation of life } \\
\text { - Personal growth } \\
\text { - Enhanced self-worth }\end{array}$ & $\begin{array}{l}\text { - Feeling like a better person or hero } \\
\text { - Being seen by others as a hero }\end{array}$ & $\begin{array}{l}\text { - Strengthened bonds with } \\
\text { the recipient } \\
\text { - Strengthened bonds with } \\
\text { family and friends }\end{array}$ \\
\hline
\end{tabular}

(Adapted from: Tong A, Chapman JR, Wong G, et al.: The motivations and experiences of living kidney donors: a thematic synthesis. Am J Kidney Dis 2012, 60(1):15-26) [19]. 
addition, $2 \%$ to $9 \%$ of kidney donors report problems getting health, life, or disability insurance after donation and nearly $12 \%$ report stress regarding future health insurability $[27,29]$. In liver donors, a study from Germany reported that $3 \%$ were denied life insurance due to their donation [30].

Gill et al. [31••] recently sought to quantify donor financial burden more precisely. They used census tract data on median household income levels to estimate donor (and recipient) income in a large series of living donor transplants captured in the U.S. Renal Data System. Using a conservative estimate that a kidney donor's direct out-of-pocket expenses total approximately $\$ 5000$ [32], they showed that this cost is greater than one month's income for $76 \%$ of donors. They also demonstrated that most recipients have modest median household incomes that are similar to their donors' income levels. Thus, recipients would likely have limited ability to help their donors cover even those expenses that recipients are allowed to cover under the U.S. National Organ Transplantation Act, including out-of-pocket costs and lost wages.

Other recent studies have focused on identifying segments of the donor population at greatest risk for financial burdens. McGrath et al. [33] show in a detailed qualitative report that Australian kidney donors from rural settings incur greater costs for travel and accommodations, loss of income due to missed work, and costs of testing, since testing at local facilities may not be covered by the transplant program or recipient insurance. Similar issues are likely to arise in other countries. In particular, financial and logistical burdens to donors are among the most often-cited factors believed to hamper followup care of living donors in the U.S. [34, 35••]

The risks of financial impacts both pre-donation and postdonation are magnified in ethnic/racial minority donors. Purnell et al. [36] summarized recent evidence, reviewing the socioeconomic barriers and impacts that arise at the stages of kidney donor identification, evaluation, and donation in the U.S. For example, the fact that ethic minority donors are less likely to have health insurance at donation sets the stage for a cascade of potential financial hardships should donors develop ongoing health problems, miss additional work, and accrue other costs in the wake of donation. Given that ethnic minorities comprise a disproportionately large percentage of kidney transplant candidates, it is imperative that barriers such as donor access to health insurance not serve to preclude donors from helping patients in need $[25,26]$. Rather, policy-based initiatives are needed to ensure that these generous individuals have healthcare coverage for the long-term post-donation [26].

Because the literature on financial impacts in living donation remains small and largely limited to North American cohorts, it is not known whether the findings are generalizable. Additionally, the data largely come from donors' retrospective reports, requiring accurate recall of historically incurred costs [11 1 . There has been almost no consideration of financial impacts in liver donors, or financial burden and hardship among donors' family members. Finally, although it is presumed that financial issues will affect donor ability or willingness to obtain follow-up health monitoring and care, there remains little direct evidence demonstrating this [37].

Special Psychosocial and Financial Issues in Unrelated Donors

The small literature to date provides somewhat mixed evidence on whether unrelated donors' psychosocial or financial outcomes differ from those in related donors. Gore et al. [38] recently examined census tract data for a national cohort of U.S. kidney donors and found that unrelated donors had higher socioeconomic status than did related donors. This suggests that unrelated donors might have a greater financial "cushion" for donation. Rodrigue et al. [28•] collected followup survey data from a sample of nondirected and directed anonymous kidney donors and a comparison group of related donors to examine financial as well as psychosocial outcomes. The two groups reported similar levels of psychological benefits and health consequences of donation. They did not differ in perceived financial consequences, HRQOL, or satisfaction with having donated. Massey et al. [39] obtained similar survey findings. However, both reports provide some evidence that anonymous donors may be more likely than other donors to experience negative reactions from others regarding their decision to donate, and these reactions may cause donors distress.

In the only prospective study to date, Timmerman et al. [40•] found that psychological symptoms increased from predonation to post-donation in a sample of nondirected anonymous donors, particularly in the areas of depression, anxiety, somatization, hostility, and sleep problems. The increases were larger among donors with longer follow-up times. The authors suggest that the changes might represent natural fluctuations in symptoms, a hypothesis that would require the inclusion of a comparison group (e.g., related donors or nondonors) followed longitudinally in order to be tested. Finally, one small report of kidney exchange participants found no evidence that these individuals needed additional psychosocial services or practical or emotional support after donation [41]. No studies have compared outcomes in unrelated vs. related liver donors.

An important question is whether recipient outcomes would differentially affect unrelated vs. related donors. On one hand, the lack of a close connection between unrelated donors and their recipients might lead to less distress in these donors in the event of recipient morbidity or death. Alternatively, given the lessened likelihood of ongoing contact with the recipient, unrelated donors may feel even more devastated at learning of a poor recipient outcome because this might be the only specific information they have about the recipient. 
The findings in the Lentine et al. report $[18 \bullet \bullet$ are consistent with this supposition.

\section{Management of Psychosocial and Financial Outcomes}

\section{Requirements and Recommendations for Follow-up}

The routine collection of follow-up data on donor outcomes is becoming more common in European and North American countries [5, 42]. To date, most efforts focus on donor clinical and laboratory data, although one psychosocial parameter (whether donors have returned to work) is collected in the U.S., and a range of HRQOL and psychosocial parameters are targeted for future collection in a European registry [42, 43]. In the U.S., the submission of follow-up information to the Organ Procurement and Transplantation Network is required through two years post-donation [5]. The level of missing data in the submitted forms renders them of little value $[2 \cdot, 44 \bullet$, 45], and donors with missing data are more likely to have the very characteristics that increase their risk for medical problems (e.g., older age and a history of hypertension in kidney donors) [44•]. With recent policy modifications, submitted forms information must be complete (i.e., without any missing information) for the majority of kidney donors [5]. Similar requirements may go into effect for liver donors [4]. The ability of living donor programs to obtain high rates of follow-up is a subject of debate. Recent surveys of living donor kidney and liver programs show that, while follow-up (a) is viewed as important for donor safety and well-being [35••] and (b) should be expanded to include more psychosocial outcomes [35••], programs perceive significant barriers to locating and evaluating donors $[34,35 \cdot \bullet]$. Barriers include potential unwillingness among donors to participate in such evaluations $[34,35 \bullet \cdot$. Whether required follow-up constitutes yet another financial burden for donors is another concern [33, 34], although programs with high rates of follow-up generally subsidize at least some costs to donors [45].

The rationale for required follow-up stems from the transplant community's obligation to ensure donors' safety, as well as to provide data to inform future donors about the risks and benefits of donation. This is emphasized in both the education and informed consent of prospective donors, in which - consistent with consensus conference and expert recommendations $[2 \cdot, 4,46]$ - they are encouraged to have annual checkups and engage in other health promotion activities for the remainder of their lives. Yet, two recent cross-sectional follow-up studies suggest that many kidney donors do not engage in recommended activities [47, 48]. Doshi et al. [47] assessed 103 African American donors from two centers at an average of six years post-donation and found that $41 \%$ were hypertensive; of these, over half (52\%) were not receiving treatment, and another $17 \%$ had inadequately controlled blood pressure on medication. Myaskovsky et al. [48] evaluated 85 donors who averaged two years post-donation and found that $20 \%$ reported that they did not have regular medical check-ups, although this was a significantly smaller percentage than the $47 \%$ who (at follow-up) reported that they did not have regular check-ups before donation. In addition, $54 \%$ reported that they did not exercise regularly (vs. $43 \%$ before donation), and $25 \%$ were obese (vs. $18 \%$ before donation). Among the donors who had post-donation check-ups, $6 \%$ reported that their blood pressure was not checked, $26 \%$ did not have their blood sugar checked, and $35 \%$ reported not having their urine checked. Findings from these studies require verification in larger cohorts followed prospectively. In addition, factors that contribute to donor difficulties with health monitoring and maintenance-including, for example, financial factors - must be ascertained before strategies can be developed to increase these activities.

A recent consensus conference on the follow-up care of living kidney donors suggested that rather than requiring U.S. living donor programs to collect extensive medical or psychosocial follow-up data. Specific registries or long-term followup research efforts should be devoted to the collection of a full range of donor psychosocial and financial outcomes and their relationships with —or increased risk due to - other medical outcomes $[2 \bullet, 11 \bullet]$. This recommendation would address limitations in the evidence that we noted earlier, namely, that although subgroups of living donors may be at heightened risk for psychosocial and financial impacts of donation, we have very limited ability to identify such individuals prospectively. Moreover, there is a dearth of such information in liver donors or in the very small populations of other types of living donors (e.g., lung donors).

\section{Management Strategies for Psychosocial and Financial Outcomes}

Approaches to optimize donor psychosocial and financial outcomes come primarily from anecdotal accounts of and recommendations for clinical and educational activities. For example, based on their synthesis of qualitative studies of kidney donors' reactions to the donation experience, Tong et al. developed an educational summary that could be given to donors in order to better prepare them for what to expect emotionally from the donation experience [19, see supplemental materials]. This summary was subsequently revised and adapted as a pamphlet that might be routinely distributed by donor transplant programs [49]. Other recent reviews and recommendations focus on the content and nature of the informed consent process [50 ${ }^{\bullet}$, and the activities of the independent living donor advocate (ILDA) [51•, 52]. With respect to informed consent, findings that post-donation satisfaction and regret are related to perceptions of inadequate predonation information suggest possible deficiencies in the 
manner and/or timing of the pre-donation education and informed consent process $[50 \bullet$, 53]. Concerning the ILDA, recommendations have been made that the ILDA's role be extended to encompass post-donation follow-up, particularly with potentially vulnerable subgroups of donors [52]. Thus, as suggested by the Lentine et al. findings [18・•], increased vigilance for depressive disorders could be warranted in donors who had serious complications requiring reoperation and in unrelated donors whose recipients suffered death or graft failure. Findings noted earlier regarding BMI as a risk factor for poor physical HRQOL similarly suggest that obese donors may need heightened monitoring as well.

There have been no clinical trials testing the efficacy of increased post-donation monitoring for the identification and treatment of psychosocial problems in living donors. However, we recently developed and tested a brief telephone-based pre-donation intervention designed to prevent the development of such problems in kidney and liver donors $[8,54 \bullet \bullet]$. The intervention utilized techniques from motivational interviewing (MI) [55] to target residual ambivalence (i.e., lingering hesitation and uncertainty) about donating. A literature spanning over 20 years has shown such ambivalence to be prevalent and to be a key risk factor for poor post-donation outcomes in several psychosocial domains, including somatic complaints, psychological distress, and interpersonal relationship strains $[8,56]$. We compared prospective donors randomized to receive the MI intervention to those in an active comparison condition (health education) or receiving standard pre-donation care. By three months post-donation, MI participants reported fewer physical symptoms, lower rates of fatigue and pain, shorter recovery times, and fewer unexpected medical problems than other donors. They also had a lower rate of anxiety symptoms and fewer unexpected familyrelated problems. These promising findings from donors at a single center suggest that a broader test involving multiple living donor programs would be warranted as a next step in establishing intervention effectiveness.

We know of no formal tests of interventions to address the negative financial impacts of donation. A recent systematic review of public attitude studies showed a preference among members of the general public for reducing financial disincentives (i.e., removing donor-incurred burdens) as opposed to providing financial incentives for living donation [57]. Indeed, legislation adopted in some countries has sought to achieve this goal, leading to "natural experiments," in which data from before to after the legislative changes were examined in order to assess potential impact on donation rates. For example, Boulware et al. [58] found that rates of unrelated (but not related) donation increased from before to after enactment of U.S. federal and state legislation in the late 1990s supporting donors (including paid or unpaid leave for extended time periods and tax benefits). Most recently, Lavee et al. [59•] demonstrated that there has been a marked increase in living donation rates with the passage of new legislation in Israel. It, among other components, prioritizes organ allocation to individuals who are living donors, removes disincentives for anonymous living donation by mandating reimbursement for lost wages, some coverage for transportation costs, modest insurance reimbursements and social supportive services.

\section{Conclusion}

The recent literature is noteworthy for beginning to examine long-term psychosocial outcomes in living donors, and for advancing our understanding of specific areas of psychosocial outcomes that matter most for living donors. Most work considers only kidney donors. The range of identified risk factors for post-donation psychosocial difficulties also remains relatively limited. Identification is hampered by the focus on cross-sectional follow-up assessments as opposed to longitudinal or prospective investigations. However, at least for kidney donors, findings to date point to some identifiable subgroups of donors - e.g., unrelated donors - who may require more intensive short- and/or long-term monitoring in order to identify and manage post-donation psychosocial problems. Management strategies for post-donation psychosocial outcomes have largely gone untested, but promising findings in one small clinical trial suggest that empirical evaluation of strategies for prevention or post-donation intervention could be important in order to optimize the care offered to living donors. Finally, the financial impacts are becoming increasingly apparent, and may be larger and more pervasive than previously realized. While living donor transplant programs may be able to subsidize the costs to donors of required post-donation follow-up monitoring, it is likely that financial disincentives for donation will be successfully removed only via additional national legislation or other government-mandated sources of support.

Acknowledgments Preparation of this article was supported in part by Grants U01 DK085587 and R01 DK081325 from the National Institute of Diabetes and Digestive and Kidney Diseases, and Grant IAA06-220 from the Veterans Administration Health Services Research and Development Division.

\section{Compliance with Ethics Guidelines}

Conflict of Interest Mary Amanda Dew, Larissa Myaskovsky, Jennifer L. Steel, and Andrea F. DiMartini declare that they have no conflict of interest.

Human and Animal Rights and Informed Consent This article does not contain any studies with human or animal subjects performed by any of the authors. 


\section{References}

Papers of particular interest, published recently, have been highlighted as:

- Of importance

- Of major importance

1. Dew MA, Jacobs C, Jowsey SG, et al. Guidelines for the psychosocial evaluation of living unrelated kidney donors in the United States. Am J Transplant. 2007;7:1047-54.

2. Living Kidney Donor Follow-Up Conference Writing Group, Leichtman A, Abecassis M, Barr M, et al. Living kidney donor follow-up: state-of-the-art and future directions, conference summary and recommendations. Am J Transplant. 2011;11:2561-8. This report summarizes deliberations of a consensus conference that reviewed limitations of existing data on outcomes in living kidney donors; assessed the need for donor follow-up; identified potential infrastructure needs and costs for follow-up; and explored practical options for funding of follow-up data collection in the U.S.

3. Melcher ML, Blosser CD, Baxter-Lowe LA, et al. Dynamic challenges inhibiting optimal adoption of kidney paired donation: findings of a consensus conference. Am J Transplant. 2013;13:851-60.

4. American Society of Transplant Surgeons: Medical evaluation, informed consent, and follow-up of the living liver donor: a consensus document from the AST/ASTS/NATCO/UNOS Joint Societies Work Group. Available at http://asts.org/docs/defaultsource/optn-unos/pubcmts_jswgl_recommendations_medeval informedconsent_followup_living_liver_donor.pdf. Accessed October 9, 2013.

5. Organ Procurement and Transplantation Network: Policies of the Organ Procurement and Transplantation Network, Section 12: living donation. 2013. http://optn.transplant.hrsa.gov/ PoliciesandBylaws2/policies/pdfs/policy_172.pdf. Accessed October 9, 2013.

6. McDowell I. Measuring Health: A Guide to Rating Scales and Questionnaires. 3rd ed. New York: Oxford University Press; 2006.

7. Clemens KK, Thiessen-Philbrook H, Parikh CR, et al. Psychosocial health of living kidney donors: a systematic review. Am J Transplant. 2006;6:2965-77.

8. Dew MA, Zuckoff A, DiMartini AF, et al. Prevention of poor psychosocial outcomes in living organ donors: from description to theory-driven intervention development and initial feasibility testing. Prog Transplant. 2012;22(3):280-92.

9. Dew MA, Switzer GE, DiMartini AF, et al. In: Living Donor Organ Transplantation, Tan HP, Marcos A, Shapiro R, editors. Psychosocial aspects of living organ donation. New York: Taylor and Francis; 2007. p. 7-26.

10. Parikh ND, Ladner D, Abecassis M, Butt Z. Quality of life for donors after living donor liver transplantation: a review of the literature. Liver Transpl. 2010;16:1352-8.

11. Dew MA, Jacobs CL. Psychosocial and socioeconomic issues facing the living kidney donor. Adv Chron Kidney Dis. 2012;19(4):237-43. This report provides summarizes workgroup recommendations from the 2010 Conference on Living Kidney Donor Follow-up [3] on psychosocial and socioeconomic issues facing living kidney donors. The workgroup commented on the state of the evidence, gaps in information on these issues, and important research questions for the future.

12.• Gross CR, Messersmith EE, Hong BA, et al.: Health-related quality of life in kidney donors from the last five decades: results from the RELIVE study. Am J Transplant. 2013;13(11):2924-34. This report describes long-term follow-up HRQOL data in one of the largest cohort of living kidney donors assessed to date. Donors were drawn from multiple U.S. centers. Multiple predictors and correlates of HRQOL were examined. See further description of findings in Table 1.

13.•- Takada Y, Suzukamo Y, Oike F, et al. Long-term quality of life of donors after living donor liver transplantation. Liver Transpl. 2012;18:1343-52. This report describes long-term follow-up HRQOL data in the largest cohort of living liver donors assessed to date. The study is noteworthy for a high response rate. Multiple predictors and correlates of HRQOL were examined. See further description of findings in Table 1.

14. De Groot IB, Stiggelbout AM, van der Boog PJM, et al. Reduced quality of life in living kidney donors: association with fatigue, societal participation and pre-donation variables. Transpl Int. 2012;25:967-75. This report describes long-term follow-up HRQOL data in a large series of living kidney donors from one center. The study is noteworthy for a high response rate, enhancing potential generalizability. See further description of findings in Table 1.

15. Clemens K, Boudville N, Dew MA, et al. The long-term quality of life of living kidney donors: a multicenter cohort study. Am J Transplant. 2011;11:463-9. The authors conducted a long-term follow-up study of donors from multiple sites in multiple countries. They considered HRQOL as well as some other areas of outcomes (e.g., employment). It is also one of the few studies to include a comparison group: the authors constructed a group of non-donors by asking donors to nominate other individuals. Many comparison group members had been evaluated as potential donors themselves but were unable to donate due to logistical or other nonmedical reasons. See further description of findings in Table 1.

16. Mjøen G, Stavem K, Westlie L, et al. Quality of life in kidney donors. Am J Transplant. 2011;11:1315-9. This study examined long-term HRQOL outcomes, and it is novel in including individuals from a national registry (in Norway). They also had a high response rate, enhancing potential generalizability. See further description of findings in Table 1.

17. Davis CL, Cooper M. The state of U.S. living kidney donors. Clin J Am Soc Nephrol. 2010;5(10):1873-80.

18.• Lentine K, Schnitzler MA, Xiao H, et al. Depression diagnoses after living kidney donation: linking U.S. registry data and administrative claims. Transplantation. 2012;94(1):77-83. The authors integrated data from the Organ Procurement and Transplantation Network with administrative data from a U.S. private health insurer in order to examine rates and correlates of depression diagnoses in kidney donors. The cohort is the largest examined to date in terms of mental health outcomes after donation.

19. Tong A, Chapman JR, Wong G, et al. The motivations and experiences of living kidney donors: a thematic synthesis. Am J Kidney Dis. 2012;60(1):15-26.

20. Tong A, Chapman JR, Wong G, et al. The experiences of commercial kidney donors: thematic synthesis of qualitative research. Transpl Int. 2012;25:1138-49.

21. Moniruzzaman M. "Living cadavers" in Bangladesh: bioviolence in the human organ bazaar. Med Anthropol Q. 2012;26(1):69-91.

22. Steering Committee of the Istanbul Summit. Organ trafficking and transplant tourism and commercialism: the Declaration of Istanbul. Lancet. 2008;372:5-6.

23. Rodrigue JR, Cornell DL, Kaplan B, Howard RJ. Patients' willingness to talk to others about living kidney donation. Prog Transplant. 2008:18:25-31.

24. NATCO, The Transplant Professional Organization: Living donor health care coverage, insurability and follow-up: position statement, 2006. Available at http://www.natco1.org/public policy/documents/ LivingDonorInsurability.pdf. Accessed January 4, 2012.

25. Casagrande LH, Collins S, Warren AT, Ommen ES. Lack of health insurance in living kidney donors. Clin Transpl. 2012;26(2): E101-4. 
26. Gibney EM, Doshi MD, Hartmann EL, et al. Health insurance status of US living kidney donors. Clin J Am Soc Nephrol. 2010;5:912-6.

27. Clarke KS, Klarenbach S, Vlaicu S, et al. The direct and indirect economic costs incurred by living kidney donors: a systematic review. Nephrol Dial Transplant. 2006;21:1952-60.

28. Rodrigue JR, Schutzer ME, Paek M, Morrissey P. Altruistic kidney donation to a stranger: psychosocial and functional outcomes at two US transplant centers. Transplantation. 2011;91:772-8. This study directly compares outcomes in anonymous donors to donors who had longstanding biologic or emotional relationships with their recipients. Strengths are that the donors were drawn from two centers and a wide range of HRQOL and financial outcomes were examined.

29. Yang RC, Thiessen-Philbrook H, Klarenbach S, et al. Insurability of living organ donors: a systematic review. Am J Transplant. 2007;7: 1542-51.

30. Sotiropoulos GC, Radtke A, Molmenti EP, et al. Long-term followup after right hepatectomy for adult living donation and attitudes toward the procedure. Ann Surg. 2011;254(5):694-701.

31.• Gill JS, Gill J, Barnieh L, et al. Income of living kidney donors and the income difference between living kidney donors and their recipients in the United States. Am J Transplant. 2012;12:3111-8. The authors examine a large national cohort of kidney recipients and their donors in order to evaluate household income levels, based on census tract data. Comparisons of recipients' and donors' median income levels are informative for evaluating the potential for recipients to cover donor expenses associated with donation and thereby for understanding the likely degree of financial burdens assumed by donors.

32. Gaston RS, Danovitch GM, Epstein RA, et al. Limiting financial disincentives in live organ donation: a rational solution to the kidney shortage. Am J Transplant. 2006;6:2548-55.

33. McGrath P, Holewa H. "It's a regional thing": financial impact of renal transplantation on live donors. Rural and Remote Health (Online) 2012, 12:2144. Available at: http://www.rrh.org.au. Accessed October 9, 2013.

34. Mandelbrot DA, Pavlakis M, Karp SJ, et al. Practices and barriers in long-term living kidney donor follow-up: a survey of U.S. transplant centers. Transplantation. 2009;88(7):855-60.

35.• Waterman AD, Dew MA, Davis CL, et al. Living donor follow-up attitudes and practices in U.S. kidney and liver donor programs. Transplantation. 2013;95(6):883-8. The authors report on a national survey of living donor programs in which respondents reported on factors that make donor follow-up important as well as render it difficult to complete. The study advances over a previous survey by Mandelbrot et al. [33] in including liver donor programs. The study achieved a relatively high response rate.

36. Purnell TS, Hall YN, Boulware LE. Understanding and overcoming barriers to living kidney donation among racial and ethnic minorities in the United States. Adv Chron Kidney Dis. 2012;19(4):244-51.

37. Friedman AL, Friedman EA. A step toward solving the long-term care dilemma for living kidney donors. Transplantation. 2012;94(10):988-9.

38. Gore JL, Singer JS, Brown AF, Danovitch GM. The socioeconomic status of donors and recipients of living unrelated renal transplants in the United States. J Urol. 2012;187:1760-5.

39. Massey EK, Kranenburg LW, Zuidema WC, et al. Encouraging psychological outcomes after altruistic donation to a stranger. Am J Transplant. 2010;10:1445-52.

40. Timmerman L, Zuidema WC, Erdman RAM, et al. Psychologic functioning of unspecified anonymous living kidney donors before and after donation. Transplantation. 2013;95(11):1369-74. This is the largest study to date that has examined anonymous kidney donors. A key strength is its prospective design, allowing for changes to be examined across the course of the donation process.
41. Kranenburg L, Zuidema W, Vanderkroft P, et al. The implementation of a kidney exchange program does not induce a need for additional psychosocial support. Transpl Int. 2007;20:432-9.

42. Manyalich M, Menjívar L, Yucetin L, et al. Living donor psychosocial assessment/follow-up practices in the partners' countries of the ELIPSY Project. Transplant Proc. 2012;44: 2246-9.

43. Manyalich M, Ricart A, Martinez I, et al. EULID project: European living donation and public health. Transplant Proc. 2009;41(6): 2021-4.

44. - Ommen ES, LaPointe Rudow D, Medapilli RK, et al. When good intentions are not enough: obtaining follow-up data in living kidney donors. Am J Transplant. 2011;11:2575-81. The authors performed an analysis of factors associated with missing data on the forms that living donor programs are required to submit to document followup of living donors. An understanding of which donors are likely to have missing data is critical for evaluating bias in the follow-up data and for targeting donor subgroups for which additional efforts at follow-up are needed.

45. Dew MA, Olenick D, Davis CL, et al. Successful follow-up of living organ donors: strategies to make it happen. Prog Transplant. 2011;21(2):94-6.

46. Tong A, Chapman JR, Wong G, et al. Screening and follow-up of living kidney donors: a systematic review of clinical practice guidelines. Transplantation. 2011;92(9):962-72.

47. Doshi MD, Goggins MO, Li L, Garg AX. Medical outcomes in African American live kidney donors: a matched cohort study. Am J Transplant. 2013;13(1):111-8.

48. Myaskovsky L, Doebler DA, Posluszny DM, et al. Rates and correlates of health maintenance behaviors after living kidney donation. Prog Transplant. 2012;22(2):147-54.

49. Thomas SM, Lentine KL, Garg AX. Preparing potential living kidney donors for what they will experience emotionally. Am J Kidney Dis. 2012;60(1):1-2.

50. Gordon EJ. Informed consent for living donation: a review of key empirical studies, ethical challenges and future research. Am J Transplant. 2012;12:2273-80. The author provides a comprehensive review of the literature and suggests specific areas for which research is most needed.

51. Steel J, Dunlavy A, Friday M, et al. A national survey of independent living donor advocates: the need for practice guidelines. Am J Transplant. 2012;12:2141-9. The authors conducted a survey to delineate the practices of independent living donor advocates in the United States with an eye toward the development of recommendations for general practice. Those recommendations are described in Steel et al. [49].

52. Steel JL, Dunlavy A, Friday M, et al. The development of practice guidelines for independent living donor advocates. Clin Transpl. 2013;27:178-84.

53. Valapour M, Kahn JP, Bailey RF, Matas AJ. Assessing elements of informed consent among living donors. Clin Transpl. 2011;25:185-90.

54.• Dew MA, DiMartini AF, DeVito Dabbs AJ, et al. Preventive intervention for living donor psychosocial outcomes: feasibility and efficacy in a randomized controlled trial. Am J Transplant. 2013;13:2672-84. There are no evidence-based interventions to prevent adverse psychosocial consequences after living kidney or liver donation. The authors conducted a single-site randomized controlled trial of a brief intervention offered before donation. Donors were then followed to examine psychosocial outcomes after donation. Results indicated that the intervention was feasible and efficacious, and suggested that a large-scale trial of the intervention is warranted.

55. Miller WR, Rollnick S. Motivational interviewing: Preparing people for change. 3rd ed. New York: Guilford; 2012. 
56. DiMartini A, Cruz Jr R, Dew MA, et al. Motives and decision making of potential living liver donors: comparisons between gender, relationships and ambivalence. Am J Transplant. 2012;12(1): 136-51.

57. Hoeyer K, Schicktanz S, Deleuran I. Public attitudes to financial incentive models for organs: a literature review suggests that it is time to shift the focus from "financial incentives" to "reciprocity. Transpl Int. 2013;26:350-7.

58. Boulware LE, Troll MU, Plantinga LC, Powe NR. The association of state and national legislation with living kidney donation rates in the United States: a national study. Am J Transplant. 2008;8(7): 1451-70.

59. Lavee J, Ashkenazi T, Stoler A, et al. Preliminary marked increase in the national organ donation rate in Israel following implementation of a new organ transplantation law. Am J Transplant. 2013;13: 780-5. The authors analyzed data from before to after enactment of a new law in Israel and found that the rate of living donation showed a dramatic increase. The law removed many financial disincentives to living donation. The paper discusses effects of the law on deceased donation as well. 